\title{
Research on Optimal Strategy of Agricultural Products Marketing
}

\author{
Linyan Hu \\ School of Economics and Management, Zhejiang Ocean University, Zhoushan, 316022, China
}

\begin{abstract}
With Agriculture occupies a high proportion of the national economy. National economic growth is mainly based on agricultural economic development. Optimizing agricultural product marketing strategies can greatly increase agricultural product sales, increase farmers' income, help farmers find employment, and promote rural economic development. Therefore, studying how to optimize the marketing strategy of agricultural products has great value and practical significance. This article analyzes the main problems in the current agricultural product marketing through the research of the current situation of agricultural product marketing and the existing model, and then proposes the strategy of optimizing agricultural product marketing, and strives to accelerate the development of the rural economy, construct modern agriculture, and promote the implementation of the rural revitalization strategy. Finally, make a general recommendation on the effective measures to ensure the optimization strategy of the marketing model and how to implement it smoothly.
\end{abstract}

Keywords: Agricultural product marketing, Optimization strategy, Safety precautions.

\section{Introduction}

The key to rural revitalization and poverty alleviation is to solve the problem of agricultural product sales, increase agricultural product sales, optimize agricultural product marketing and production models, promote a large number of agricultural products, develop agriculture in depth, and promote agricultural economic development. Optimize agricultural product marketing channels, provide solutions for unsalable agricultural products, understand the shortcomings of traditional sales methods, simplify the production and sales of agricultural products, reduce agricultural product transaction costs, strengthen the quality control of rural agricultural products, and ultimately help farmers increase income and lead farmers out of poverty and become rich. Agricultural product marketing is a key factor in the development of agricultural economy. Agricultural economic benefits and farmers' income are closely related to the efficiency of agricultural product marketing models. With the development of the Internet, the traditional marketing model has been unable to meet the needs of consumers. It is necessary to keep up with the times and optimize the marketing strategy of agricultural products on the original basis. Next, this article will do a general research and analysis on the current situation of agricultural product marketing and how to improve the agricultural product marketing model through effective measures.

\section{Analysis of the Current Situation and Problems of Agricultural Product Marketing}

\subsection{Agricultural Products are Highly Regional}

Taking household production as a unit, inventory backlog coupled with malicious market competition, especially in the harvest season, is easy to form "partial saturation", so that the unsalable agricultural products are becoming more and more serious.

\subsection{Agricultural Products are not Produced in Accordance with Market Rules}

The market economy emphasizes the balance of supply and demand, and the law of value requires that agricultural production activities must be observed, and changes in the relationship between supply and demand also need to be adapted in order to coordinate production and demand. In most of our rural areas, farmers often judge the agricultural product market based on their personal experience and intuition, which leads to huge fluctuations in agricultural product prices and a huge waste of social resources.

\subsection{The Concept of Agricultural Product Sales is Backward}

Farmers still have more traditional thinking in agricultural products management, focusing only on planting agriculture, and they are still lacking in agricultural circulation and marketing. The sales method is generally direct sales at a reduced price, or sales by way of door-to-door purchases by customers, who are still unfamiliar with Internet marketing methods and lack network knowledge.

2.4 The Construction of Infrastructure such as Agricultural Product Storage and Logistics is Backward

The production of agricultural products is highly seasonal and regional, and the hell is widely distributed. In a particular season, a large number of agricultural products are often listed for trading. However, due to imperfect logistics facilities, coupled with limited shelf life and high transportation costs, a large number of agricultural products are prone to unsalable sales. Over time, agricultural products that are not shipped will rot and deteriorate. The consequence is to cause certain economic losses and mental pressure to farmers, and farmers' enthusiasm for production is also greatly reduced.

\subsection{Agricultural Product Brand Concept is Backward}

Most farmers in our country only focus on immediate benefits, 
their business scope is narrow, it is difficult to adapt to market demand, and they have no brand concept. Therefore, during the harvest season, a large number of low-priced agricultural products often occur, but the market feedback is still not ideal. In order to stand out among the many products, the concept of agricultural products must be established.

\section{The Status Quo and Problem Analysis of Agricultural Products Marketing Mode}

Commodity value circulates in the three links of producer-sales channel-consumer, which is regarded as the operating mechanism of agricultural product sales. The marketing model includes these three links. It is launched with the goal of consumer purchase needs. The starting point is agricultural product producers, providing agricultural products that meet the needs of intermediaries and consumers, and the end point is consumers, purchasing agricultural products for the purpose of satisfying all their functions. The use of strategies and the number of circulation links affect the efficiency of the sales model. At present, the main marketing channels for agricultural products are the following three marketing models.

\subsection{Model with "Hypermarket" as the Channel}

The main channel for consumers to buy agricultural products is still in large supermarkets. Farmers' professional cooperatives are the main suppliers, and the main marketing model is the "agricultural supermarket docking" model. The government strongly supports this model. Farmers' professional cooperatives or wholesalers sign contracts with supermarkets to purchase products regularly and on time. Under this model, the rights and interests of farmers are protected, and part of the income of agricultural products is collected by farmers in advance, and production risks are reduced accordingly; product prices are locked in advance by supermarkets, product costs are also controlled, and business risks are also reduced.

This model also has shortcomings. The cold chain logistics system must be perfect for the transportation of agricultural products from the place of origin to the place of sale. For example, the cold chain logistics infrastructure is not perfect, and the cold chain logistics capacity of production area and sales area is not balanced, and effective docking cannot be carried out. Due to the small scale of transportation and unstable transportation, third-party logistics companies do not pay attention to the cold chain logistics infrastructure of the production area, and are unwilling to invest in the cold chain logistics infrastructure of the production area, so that the cold chain logistics capabilities and requirements do not meet, resulting in the failure of smooth marketing.

\subsection{Model with "Farmer's Market" as the Channel}

The farmer's market is currently one of the most common channels for farmers to sell agricultural products. It mainly uses the "individual farmer + wholesaler + retailer" model, with complicated intermediate processes and backward marketing concepts. Although with the development of the Internet, there are more and more agricultural product marketing models, but the "farmer + wholesaler + retailer" model still accounts for a large proportion of agricultural product sales. The agricultural product wholesale market occupies an important position in the circulation of agricultural products. The agricultural product wholesale market can be divided into the sales wholesale market and the origin wholesale market. In places with backward production methods, agricultural products cannot be produced on a large scale, and agricultural products do not meet the purchase standards of large supermarkets. Mainly rely on small vendors to buy. In addition, farmer's markets are mostly located in residential areas to facilitate consumers to purchase. This channel is the most common in agricultural product marketing.

This model also has some shortcomings. First, the sales concept is backward. Farmers are out of touch with the consumer market. Farmers only pay attention to production and wait for the middlemen to purchase after production, without paying attention to processing and marketing. The government encourages farmers to produce, provides advanced technical support, and gives them guidance on production skills, but there is little training in marketing knowledge, and operators have little understanding of marketing knowledge, so that the output increases every year and the slow-moving phenomenon is becoming more and more serious. Second, there are many intermediate links. There are wholesalers and retailers between farmers and consumers. They will incur a certain cost. In the process of changing hands many times, time will be consumed soon, and the loss and quality of agricultural products will also be reduced. The increase in middlemen will bring about agricultural products. Consumers' functions will not increase, and the corresponding rents, transportation costs, manpower and time will increase. Producers and consumers do not need these costs. As sales costs increase, consumers' willingness to buy will also decrease, and the economic benefits of middlemen and consumers will also suffer due to the decrease in purchases. The producer + wholesaler + retailer model goes through a variety of links, and finally reaches the consumers. Transportation, storage, and labor costs are needed in the middle. However, the agricultural products not only cause no other uses, but the products will also have certain losses.

\subsection{Mode with "Internet Marketing" as the Medium}

The use of the Internet platform to achieve agricultural product transactions and the application of online sales to agricultural product marketing have opened up broader sales channels, not limited by time and geographic location, expanded the circulation radius of agricultural products, made agricultural products more transparent, and reduced the lack of sales channels. And unnecessary waste. Integrating the industrial chain and realizing the integration of production, supply and marketing of agricultural products will improve the quality of agricultural products to a certain extent, establish the brand image of agricultural products, promote the development of agricultural economy, and accelerate the 
realization of rural revitalization. In recent years, network marketing has attracted more and more attention, and the network marketing of agricultural products will become the main marketing method for agricultural products in the next few years.

At present, there are some problems in the online marketing of agricultural products. First, most farmers' thinking is still in the past, they have very little knowledge of the Internet, some have not purchased electronic equipment at home, and are basically unfamiliar with the use of online platforms, and lack of online marketing. Talents, lack of marketing skills, seldom use the Internet to communicate with consumers, so that consumer needs cannot be met in time, leading to a decline in satisfaction. Second, the construction of agricultural informatization is backward. Many farmers and agricultural units obviously do not meet the conditions for the smooth implementation of agricultural product marketing in terms of network equipment and configuration. Agricultural product information management is not standardized, and the blind and random release of agricultural product information has led to low quality of agricultural product information resources, information asymmetry, and chaotic information management. It will soon become more difficult for farmers and agricultural enterprises to collect information, and it also makes some consumers doubtful. Attitude towards agricultural product marketing. Third, the logistics and distribution of agricultural products are difficult. Logistics distribution is a guarantee for the smooth implementation of agricultural product network marketing. Agricultural products have the characteristics of freshness, and their shelf life is short and easy to deteriorate. The logistics and distribution requirements of agricultural products are often higher than those of ordinary commodities. Due to cost considerations, my country's agricultural products are generally transported in normal temperature and natural forms, which causes huge losses to agricultural products in transportation projects. The incomplete logistics system is one of the most important factors in the marketing of agricultural products.

\section{Suggestions on the Optimization Agricultural Product Marketing}

\subsection{Improve the Market Competitiveness of Agricultural Products in Many Ways}

First, improve the quality of agricultural products. With the development of the economy and the improvement of living standards, more and more consumers have put forward new requirements for the quality of agricultural products. Good quality has become a new consumer demand. An important strategy to occupy the market is to introduce, cultivate and promote high-quality products. For agricultural products, weed out bad varieties and outdated production technologies, and win with quality.

Second, control production costs and improve production efficiency. Market competition mainly depends on price. If the price of similar agricultural products is low, the competitiveness will be correspondingly strong. The basis of price is production cost. Only when costs are reduced can price competition have an advantage. To improve market competitiveness, it is necessary to integrate resources, adopt new technologies, implement large-scale operations, reduce cost input, control costs, increase output rates, and implement low-cost and low-price strategies to achieve economic benefits.

Third, highlight product differentiation. If there is no advantage in quality and price, as long as it is distinguished from other agricultural products and has its own characteristics, it can also show a competitive advantage. Because the production of agricultural products is seasonal and contradicts the equilibrium of market demand, this business opportunity can be used to implement anti-seasonal supply and earn a high price difference. The main ways to supply off-season are: practice high-tech planting and put products on the market in advance; use storage to keep fresh to extend the sales period, and turn production peak season sales into consumption peak season sales; develop varieties suitable for production in different seasons, and implement multi-variety off-season production and listing.

\subsection{Strengthen the Use of Agricultural Product Network Marketing}

First, strengthen the farmers' online marketing concept. Regularly train farmers on network knowledge, help farmers accept the concept of network marketing, organize farmers to establish network cooperatives, introduce senior talents in e-commerce marketing, and promote agricultural development in poverty-stricken areas. Encourage professional talents to go to the grassroots level and invest in the Internet marketing of agricultural products to provide technical support for rural e-commerce.

Second, increase investment in rural infrastructure construction. In order to develop our agriculture under the background of rural revitalization, we must improve the rural infrastructure. On the one hand, the logistics and distribution infrastructure should be improved. It is necessary to vigorously improve the transportation facilities such as roads and railways, broaden the network radius, and provide favorable logistics conditions for the network marketing of agricultural products. On the other hand, to improve the hardware level of computer equipment, the Internet relies on computers to function. At present, some rural economies are still relatively backward and need to invest in infrastructure such as computers.

Third, "Internet+" is combined with agricultural production. The Internet has the characteristics of rapid acquisition of information across regions. In all aspects of agricultural production, the Internet can be used to obtain effective information, and high-level information can be obtained through the Internet to improve the efficiency of agricultural production. Combine "Internet+" agriculture with new-type agriculture, and cultivate a group of farmers with new-type Internet agriculture thinking through Internet training, awards, and subsidies, and drive the development of the entire village. 
Encourage poor farmers to use the advantages of online platforms to create wealth, drive economic development in poor areas, and accelerate the implementation of rural revitalization strategies.

\subsection{Multi-channel Attempts to Innovate Agricultural Product Marketing}

\subsection{1 "Agricultural products + live webcast" model}

In recent years, webcasting has received widespread attention, and major stars have joined the webcasting team and received high rewards. The advantage of webcasting is that it can be seen in person and has high credibility; timely interaction and good consumer experience; fresh and fashionable, satisfying the curiosity of customers. The use of live webcasting to promote agricultural products can greatly help build trust between consumers and farmers, and it can also quickly spread the promotion of agricultural products and brands. To play a greater role in live webcasting, web anchors are best served by well-known celebrities or corporate founders. In addition, after-sales service also needs to keep up, especially logistics and distribution to be safe, fast, and timely.

\subsection{2 “Agricultural products + adoption” model}

Adoption means that everyone adopts an agricultural product in partnership. It can be an acre of land, a tree, or an animal, subscribe for the quantity and parts, and then jointly obtain the adopted agricultural products and enjoy the fun of adoption. The leader of the adoption model is the key, and it is necessary to serve and supervise the adopted members to ensure the smooth progress of the adoption work. In addition, the adoption work must be transparent, the adoption status and information must be made public, and everyone must be aware of the entire adoption process, and fraud is not allowed.

\subsection{3 "Agricultural products + crowdfunding" model}

Selling agricultural products through crowdfunding platforms can help solve the problem of unsalable agricultural products and promote agricultural products on a large scale. You can also use $\mathrm{O} 2 \mathrm{O}$ crowdfunding, that is, without going through distributors and agents, consumers directly pre-purchase agricultural products or "adopt" agricultural products at a suitable price, so as to enjoy the experience brought by the production of agricultural products. Crowdfunding of agricultural products is actually a business model that combines Internet finance and agriculture. For merchants, the pre-purchase form is of great benefit to production plans and withdrawal of funds. Being able to participate in the production process of agricultural products and experience the fun of ecology and nature is very attractive to consumers.

\subsection{4 "Agricultural products + Wechat business" model}

Publish agricultural products planting, growth, and picking information in WeChat Moments, and publish the growth process and growth of agricultural products in the form of videos and pictures to $\mathrm{WeChat}$ Moments, so that consumers can keep abreast of the actual conditions of agricultural products. Selling agricultural products through WeChat requires the formation of a personalized brand, and the brand is used as a premium. Furthermore, WeChat Moments sells not products but people. Consumers choose to buy according to their likes and approvals out of trust. Strengthen the promotion of personal image, spread credible product information, create personal charm, and win the trust of the team and users.

\section{Guarantee Measures for the Optimization and Implementation of Agricultural Product Marketing}

\subsection{Strengthen the Supervision of the Quality of Agricultural Products}

First, establish product quality standards and increase supervision. The key to the implementation of the agricultural product marketing model lies in product quality. Random inspections of agricultural products are required from time to time. The quality of agricultural products is mainly measured by the two indicators of pesticide residue and metal content. At the same time, establish an agricultural product market access system and a market exit system, as well as an agricultural product quality and safety responsibility system to ensure the quality of agricultural products to the utmost extent.

Second, obtain product information by scanning the QR code. What consumers pay most attention to when buying products is product information. Disclosure of product information is the foundation of consumer trust. Consumers can quickly obtain information by scanning the QR code. The information obtained includes the production process of agricultural products, which is convenient for satisfying consumers' curiosity and increasing product identity. The second is to announce the sources and price fluctuations of agricultural products and the telephone number of complaints for consumers' reference. The third is the pesticide residue content, harmful substance content and each nutrient content of agricultural products that have been tested by the testing agency, and the relevant data is regularly updated in the $\mathrm{QR}$ code.

Third, establish a consumer evaluation system. As the marketing model of agricultural products becomes more and more novel and there are more and more marketing channels, the traditional agricultural product quality supervision system cannot comprehensively supervise agricultural products. At the same time, the most accurate judgment of the quality of agricultural products comes from the feelings of consumers. By establishing a consumer evaluation system and perfecting the last link of agricultural product quality supervision, producers and operators will not only be forced to take the initiative to improve product quality, but they can also adjust production and operation methods based on evaluation information. On the basis of purchasing agricultural products, consumers can also evaluate the quality of agricultural products. 


\subsection{Cultivate the Talent Team of Agricultural Product Marketing System}

First, cultivate talents for origin marketing. To solve the problem of unsalable agricultural products mainly depends on the sales of origin marketers. The relevant government departments regularly and organized training for origin marketers to combine agricultural product marketing knowledge with the cultural connotation of agricultural products, and promote marketing capabilities to achieve the effect of $1+1>2$. Appropriately adopt Internet and multimedia education methods to train marketers in production areas, or hire marketing experts to conduct professional training for sales personnel in various regions, and encourage marketers to study in rural areas with successful experience.

Second, train logistics professionals. With the development of the online economy, the scale of the logistics system is getting larger and larger, but the level of logistics services is far from meeting actual needs. There is a large shortage of logistics professionals in my country. Colleges and universities in the city should vigorously recruit logistics majors, and local logistics Enterprises cooperate in targeted training and talent transfer.

Third, cultivate marketing planning talents. The specific implementation of agricultural product marketing requires advance planning. Facing the rapidly changing market, farmers and sellers cannot adjust their marketing strategies in time. Professional marketing planning can make timely response plans to market changes in a timely manner. Marketing planning requires sound sales knowledge and solid marketing experience, and can make accurate judgments in advance of market changes. Introduce professional marketing planners, give appropriate benefits and rewards for success, and strive to retain more professional marketing planners.

\section{References}

[1] Wen Yu. Discussion on the development of direct sales model of agricultural products in my country $[\mathrm{J}]$. Foreign Economic and Trade Practice, 2013(08): 49-52.

[2] Wang Aiping. Feasibility discussion on the innovative integration of "Internet+" and agricultural product marketing models[J]. Business Economics Research, 2016(14): 134-135.

[3] Han Li. Conflict and cooperation in the protection of underwater cultural heritage[M]. Fudan University, 2017.

[4] Zhao Liling. Analysis of the transformation model of agricultural products marketing under the background of the Internet+ era-Taking Hainan Province as an example[J]. Agricultural Economics, 2018(08): 129-131.

[5] Cheng Bin, Li Xuefeng, Zhang Meizhen. Analysis on the network marketing model of agricultural products under the Internet + horizon[J]. Agricultural Economics, 2018(03): 128-129.

[6] Guo Hai, Peng Bo. Problems and countermeasures of Internet + agricultural products marketing[J]. Rural Economy and Technology, 2019, 30(3): 158-159.
[7] Hou Yinli. Research on the construction mode of "Internet + agricultural products" network marketing system[J]. Business Economics Research, 2019, (1): 68-70.

\section{Author Profile}

Linyan Hu, born in Jiande, Zhejiang, now he is a graduate student of Zhejiang Ocean University, his research direction: Agricultural product marketing direction. 